\title{
Senescence-Induced
}

\section{Chemoresistance in Triple Negative Breast Cancer and Evolution-Based Treatment Strategies}

OPEN ACCESS

Edited by:

Ariella Hanker,

University of Texas Southwestern

Medical Center, United States

Reviewed by:

David A. Gewirtz,

Virginia Commonwealth University,

United States

Alberto Servetto,

University of Naples Federico II,

Bora Lim

Baylor College of Medicine,

United States

*Correspondence:

Anindita Chakrabarty

anindita.ac@gmail.com

Specialty section:

This article was submitted to

Breast Cancer,

a section of the journal

Frontiers in Oncology

Received: 01 March 2021

Accepted: 01 June 2021

Published: 24 June 2021

Citation:

Chakrabarty A, Chakraborty S, Bhattacharya $R$ and Chowdhury $G$

(2021) Senescence-Induced Chemoresistance in Triple Negative Breast Cancer and Evolution-Based

Treatment Strategies.

Front. Oncol. 11:674354.

doi: 10.3389/fonc.2021.674354

\author{
Anindita Chakrabarty ${ }^{1 *}$, Shayantani Chakraborty ${ }^{1}$, Ranjini Bhattacharya $^{1}$ \\ and Goutam Chowdhury ${ }^{2}$
}

${ }^{1}$ Department of Life Sciences, Shiv Nadar University, Greater Noida, India, ${ }^{2}$ Independent Researcher, Greater Noida, India

Triple negative breast cancer (TNBC) is classically treated with combination chemotherapies. Although, initially responsive to chemotherapies, TNBC patients frequently develop drug-resistant, metastatic disease. Chemotherapy resistance can develop through many mechanisms, including induction of a transient growth-arrested state, known as the therapy-induced senescence (TIS). In this paper, we will focus on chemoresistance in TNBC due to TIS. One of the key characteristics of senescent cells is a complex secretory phenotype, known as the senescence-associated secretory proteome (SASP), which by prompting immune-mediated clearance of senescent cells maintains tissue homeostasis and suppresses tumorigenesis. However, in cancer, particularly with TIS, senescent cells themselves as well as SASP promote cellular reprograming into a stem-like state responsible for the emergence of drug-resistant, aggressive clones. In addition to chemotherapies, outcomes of recently approved immune and DNA damageresponse (DDR)-directed therapies are also affected by TIS, implying that this a common strategy used by cancer cells for evading treatment. Although there has been an explosion of scientific research for manipulating TIS for prevention of drug resistance, much of it is still at the pre-clinical stage. From an evolutionary perspective, cancer is driven by natural selection, wherein the fittest tumor cells survive and proliferate while the tumor microenvironment influences tumor cell fitness. As TIS seems to be preferred for increasing the fitness of drug-challenged cancer cells, we will propose a few tactics to control it by using the principles of evolutionary biology. We hope that with appropriate therapeutic intervention, this detrimental cellular fate could be diverted in favor of TNBC patients.

Keywords: triple negative breast cancer, chemotherapy, senescence, therapy-induced senescence, senescenceassociated stemness, evolution, adaptive therapy 


\section{INTRODUCTION}

Senescence, a cellular fate originally discovered in the context of growth arrest of cultured cells, is now being recognized as an essential mediator of many physiological and pathological processes $(1,2)$. Such contradictory outcomes of senescence are explained on the basis of its dynamic and contextdependent pleotropic effects (3). The cellular plasticity and stemness reprogramming functions of senescence (in cooperation with the microenvironment) are believed to be critical for the emergence of the drug-resistant clones in many cancer types, including breast cancer (BC) (4-7).

TNBC, being one of the more heterogeneous and aggressive subtypes of $\mathrm{BC}$, is frequently treated with conventional chemotherapies (8-16). Although better chemosensitivity compared to the other BC subtypes is a key characteristic of primary TNBCs, patients with residual disease frequently experience tumor relapse $(17,18)$. Among many factors responsible for TNBC chemoresistance, contributions of cancer stem cells (CSC) and therapy-induced senescence (TIS) are wellaccepted $(10,17,19)$. According to current evidences these two phenomena are causally associated $(4,5,20)$.

Immune checkpoint inhibitor (ICI) and DNA damageresponse (DDR)-directed regimens are two fairly recent FDAapproved treatment options available for $\operatorname{TNBC}(21,22)$, benefitting only a very small number of patients $(21,23)$. Interestingly, similar to chemotherapies, efficacies of both strategies are impacted by TIS (23-26). TIS may well be a universal fate assumed by cancer cells when challenged with different types of drugs. Hence, blocking TIS might be a promising approach for better clinical management of several cancer types, especially that of TNBC $(23,27-37)$.

In the eyes of evolutionary biologists, cancer is an "open complex adaptive system" with non-linear dynamics, prone to suffer unexpected consequences of any kind of perturbations (38). Cytotoxic chemotherapies, meant to cause the highest

\footnotetext{
Abbreviations: BC, breast cancer; TNBC, triple negative breast cancer; TIS, therapy-induced senescence; SASP, senescence-associated secretory proteome; SA- $\beta$ gal, senescence-associated $\beta$-galactosidase; ROS, reactive oxygen species; OIS, oncogene-induced senescence; $\mathrm{ER}$, estrogen receptor; $\mathrm{PR}$, progesterone receptor; HER2, human epidermal growth factor receptor; ABC, ATP-binding cassette; CSC, cancer stem cell; SAS, senescence-associated stemness; ICI, immune checkpoint inhibitor; DDR, DNA damage-response; PGG, public good game; TME, tumor microenvironment; IL-1 $\alpha$, interleukin-1alpha; IL-1 $\beta$, interleukin1beta; IL-6, interleukin-6; IL-8, interleukin-8; CCL2, chemokine ligand 2; CXCL1, chemokine ligand 1; CXCL12, C-X-C motif chemokine ligand 12; TGF- $\beta$, transforming growth factor beta; MCP-1, monocyte chemoattractant protein-1; GM-CSF, granulocyte-macrophage colony-stimulating factor; VEGF, vascular endothelial growth factor; PD-1, programmed cell death protein-1; PD-L1, programmed death-ligand-1; PARP, poly (ADP-ribose) polymerase; FANCA, Fanconi anemia complementation group A; FANCC, Fanconi anemia complementation group C; FANCD2, Fanconi anemia complementation group D2; ATR, ataxia telangiectasia and Rad3-related protein; ATM, ataxia telangiectasia mutated; BRCA1/2, breast cancer 1/2; CHK1, Checkpoint kinase 1; CHK2, Checkpoint kinase 2; DSS1, deleted in split hand/split foot 1; MRN complex, Mre11, Rad50 and Nbs1 complex; NBS1, Nijmegen breakage syndrome 1; PALB2, partner and localizer of BRCA; RAD51, RAD51 recombinase; RAD54, DNA recombination and repair protein RAD54-like; RPA1, replication protein $\mathrm{A} 1$; ORR, overall objective response rate; pCR, pathological complete response.
}

amount of cancer cell death, is an "evolutionary unsound" approach. By eliminating the entire sensitive population, chemotherapies release the selective pressure on the unwanted resistant clones, a common evolutionary phenomenon termed as the "competitive release" (38-40). To slow the proliferation of the resistant population, it is necessary to alter its fitness or that of the competing populations (38). In the last part of this review, we claim that TIS is an evolutionary fitter strategy for cancer cells following chemotherapy and will attempt to establish how adaptive therapeutic strategies would help alter the fitness of the senescent cells leading to better therapeutic outcome.

\section{SENESCENCE AND ITS HALLMARKS}

Cellular senescence, induced by excessive stress, is a form of cell cycle arrest [irreversible or reversible depending on the context $(41,42)$; and the references therein]. Senescence is important for numerous physiological and pathological processes such as embryo development, wound healing, tissue repair, atherosclerosis, type 2 diabetes, aging, age-related pathologies, and reduction in regenerative potential following injury $(3,5$, 43). It can be acute (programmed, transient) or chronic (nonprogrammed, sustained) in nature, with the former affecting specific cell population and the latter being non-specific $(43,44)$ (Figure 1). Acute senescence is important for development, wound healing, and tissue repair, chronic senescence, on the other hand, often functions in limiting the proliferation of abnormal cells (43). Senescent cells are highly dynamic and heterogeneous, characterized by not one, but several interesting hallmarks as discussed below (45).

(A) Senescence cells can appear large, flattened, and irregularly shaped, which is attributed to an increased mTOR signaling (46-49) or ATF6a-mediated unfolded-protein response (50-55). In some instances, the plasma membrane protein caveolin-1 is implicated in the morphology and adherence property of senescent cells through the p38 MAP kinase pathway $(56,57)$.

(B) One of the most appreciated characteristic of senescence is an enhanced activity of the lysosomal senescence-associated beta-galactosidase (SA-ßgal) enzyme, due to either increased expression of the gene GLB1 or increased lysosomal biogenesis (58). SA- $\beta$ gal cleaves the $\beta$-D-galactose residues in $\beta$ - $D$ galactosides, such as 5-bromo-4-chloro-3-indoyl- $\beta$ - $d$ galactopyranoside (X-gal). In normal cells, SA- $\beta$ gal is active at $\mathrm{pH} 4$, but in senescent cells, its catalytic activity is detectable at suboptimal pH $6(5,43,59,60)$. However, because of the robust signal detected with certain non-senescent, healthy cells in developing embryo, strong SA- $\beta$ gal-positivity may not necessarily be the best indication of senescence (58).

(C) Accumulation of old and dysfunctional mitochondria due to a reduction in mitophagy is another feature of senescent cells. This is associated with enhanced ROS production through release of mitochondrial enzymes, such as endonuclease $G$ (60-62). 


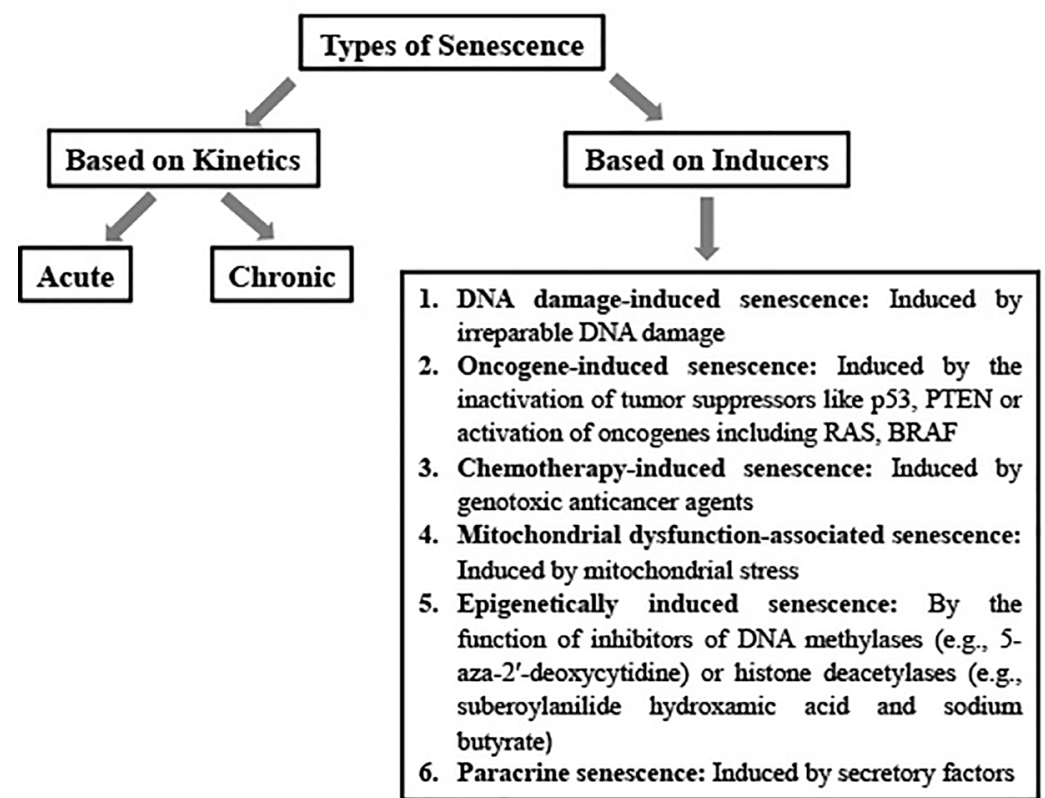

FIGURE 1 | Schematic representation of types of senescence.

(D) Senescent cells possess decondensed heterochromatin and cytoplasmic chromatin fragments (CCFs), due to a reduction in nuclear structural protein Lamin B1. They attempt to compensate these by forming the senescenceassociated heterochromatin foci (SAHF) (63-66).

(E) Upregulation of cell cycle inhibitors p16INK4a, p15INK4b, p21CIP contribute to the senescence-associated growth-arrested phenotype. Furthermore, a chronic DNA damage-response (DDR) pathway activation is detectable in most senescent cells (44). Additionally, senescent cells are apoptosis-resistant due to the upregulation of the BCL-2 family of pro-survival factors (67).

(F) The multifunctional senescence-associated secretory phenotype/SASP is an unequivocal marker of senescence (68). SASP comprises of growth factors, matrix modifying enzymes, cytokines, chemokines, etc. (68-70). The secretory phenotype also includes extracellular vesicles (sEVs) similar to exosomes that participate in cell-to-cell communication through various types of cargos (proteins, lipids, and nucleic acids). Recent reports imply that sEVs are important for tumorigenesis and age-related pathologies $(59,71)$.

(G) Senescent cells attract, activate, and anchor to immune cells through several cytokines and chemokines (example, IL-6, IL- 8 , IL-1 $\beta$, TGF- $\beta$, GM-CSF, MCP-1), which ultimately lead to their clearance [(72) and the references therein]. This is called senescent surveillance. Cells of both innate and adoptive immune systems (macrophage, B and T cells, NK cells, mast cells, neutrophils, etc.) are involved in this process [(72) and the references therein]. Molecular features of cell dysfunction and death (DAMPs) produced by senescent cells also facilitate their immune cell-mediated clearance (73). During aging and age- related diseases, senescent cells accumulate in several tissues/ organs. Although, this coincides with age-associated impaired or overwhelmed immune system, it is not entirely clear whether dysfunctional immune cells lead to accumulation of senescent cells or senescent cells accumulation leads to immune system failure $(72,74-79)$. The complex feedback interaction between SASP components and immune cells endows an overall proinflammatory and pro-senescent environment in aged animals [(72) and the references therein]. Improving immune-clearance of senescent cells could alleviate many adverse symptoms of old age and other diseases.

(H) Senescence, in some instances, involves autophagy, although the relationship between autophagy and senescence is far from straightforward. Autophagy is a catabolic process important for maintaining cellular homeostasis under conditions of nutrient deprivation. Similar to senescence, autophagy is stimulated by radiation, chemotherapy, telomere shortening, and oncogene activation, shares some common features, and serves similar cytoprotective roles $(80,81)$. Increased autophagic vacuole formation coincides with heightened SA- $\beta$-gal activity in aging fibroblasts (82). Autophagy marker expression overlaps with those of senescence in endothelial and dental pulp cells $(83,84)$ and in bile duct cells of patients with biliary cirrhosis $(85,86)$. Increased autophagic activity is responsible for the death of senescent keratinocytes $(87,88)$. A study examining the direct relationship between autophagy and oncogene-induced senescence (OIS) by Young et al. showed that autophagy speeds up senescence, although once set in, the latter could not be reversed by blocking the former (89). This was also verified in post-chemotherapy senescent cancer cells (90). At a molecular 
level, both phenomena are controlled by overlapping signaling pathways involving ROS generation, DDR activation, p53 and p21 tumor suppressor induction $(89,90)$. It is possible that autophagy is induced to help cells produce energy in anticipation of the senescence-associated growth arrest (80). Some reports suggest an inverse relationship between autophagy and senescence, such that the inhibition of the former facilitates the latter, particularly in the context of oncogene and chemotherapyinduced senescence (91-93). This could be explained if senescence serves as a backup for cells failed to initiate autophagy to survive external and internal stressors (80). Nevertheless, to firmly decide whether or not autophagy is essential for senescence induction, more experiments are required, such as those i) conducted in cells with defective apoptosis, ii) involve spatial and temporal regulation of autophagy and senescence, and iii) consist of careful monitoring of the two simultaneously (80).

(I) Classically, the $\mathrm{p} 53 / \mathrm{p} 21$ and $\mathrm{p} 16 / \mathrm{RB}$ tumor suppressor pathways are responsible for the induction and maintenance of senescence (94). According to recent literature however, senescence is a form of stress response influenced by many effector pathways (41). Different phenotypic changes autonomous or non-autonomous to the senescent cells, are triggered by specific combinations of these effector programs. For example, the DDR and SASP trigger autonomous changes in senescent cells via effector signaling pathways p38 and PI3K/ $\mathrm{AKT} / \mathrm{mTOR}$ and chromatin level alterations such as formation of SAHF and PML bodies. The non-autonomous/paracrine changes to the senescent microenvironment are mediated through SASP by affecting immune response, fibrosis, wound healing, angiogenesis, cellular plasticity, etc. Activation of chronic DDR signaling pathway is important for SASP production and depletion of several DDR-associated proteins negatively affects expression of several key SASP components such as IL-6, IL-8, and GRO family members. Transcription factors NF- $\kappa \beta$ and CCAAT enhancer-binding protein $\beta(\mathrm{C} / \mathrm{EBP} \beta)$ are involved in global regulation of SASP constituents $(41,94,95)$.

Interestingly, the long list of detrimental effects of senescence as it pertains to aging and age-related diseases poses a fundamental question: why would such a maladaptive process evolve in human, especially when many organisms do not experience aging/senescence (96)? This paradox is a topic of intense discussion and outside the scope of this review. According to the most straightforward theory, senescence induction is selected for in early life to prevent accumulation of damaged cells and support healing following injuries. As the force of natural selection decreases with age, the efficiency of senescence cell clearance reduces and its adverse effects become evident. This is comparable to the antagonistic pleiotropy theory of aging which posits that natural selection drives evolution by selecting genes that provide early life benefit to maximize reproductive fitness, but once the reproductive period ends, the organism enters a window of weakened selection leading to hyper-inflammation, immune evasion, tumor promotion, and other age-related disorders $(97,98)$.

\section{SENESCENCE IN MALIGNANT TRANSFORMATION AND CANCER THERAPY}

Malignant transformation is characterized by uncontrolled cellular proliferation through gain of oncogenes or loss of tumor suppressors (99). However, it does not always lead to overt cancer, as is the case with dormant benign tumors, such as melanocytic nevi exhibiting proliferative arrest (100). One of the contributing factors to this phenomenon is oncogene-induced senescence/OIS, first reported with the Ras oncogenetransformed human primary lung fibroblast IMR90 and mammary epithelial cells $(101,102)$. OIS, stimulated by activated oncoproteins or inactive tumor suppressor proteins such as BRAF, RAS, AKT, E2F1, cyclin E, PTEN, or NF1, occurs prematurely in absence of telomere shortening (103), however, depends on the extent of oncogene overexpression (104). Persistent DNA damage, tumor suppressors p53, pRB, and several microRNAs are key regulators of OIS (103). In addition to growth arrest, OIS is characterized by SA- $\beta$-gal activation, SASP production, and stimulation of autophagy (103).

It is believed that OIS is a fail-safe tumor-suppressive mechanism (105). However, it can also be tumor-promoting (106), particularly through the involvement of different SASP components $(68,103)$. For example, TGF- $\beta$ and MCP1 propagate growth-arrested phenotype in the neighboring nonsenescent cells (107), while MCP1 and CXCL1 promote immune clearance of senescent cells by attracting NK cells and tumorsuppressive M1 macrophages $(108,109)$. Again, VEGF, IL-6, IL8, and CXCL1 support tumorigenesis through their positive effects on angiogenesis, invasion, and CSCs (110-113). By recruiting M2 macrophages and immature myeloid cells, MCP1 is able to create an immunosuppressive environment in the vicinity of the senescent cells, helping them to escape immune-clearance $(114,115)$.

As the long-term presence of senescent cells from OIS can promote tumorigenesis, their direct removal or prevention of SASP production is perceived as a tumor-protective strategy. Two major classes of therapeutic agents targeting senescent cells are available: senocidals (further categorized as senolytics and senotopics) and senomorphics. These include varieties of natural products, endogenous compounds, investigational and approved drugs [(116) and references therein]. Senocidals eliminate senescent cells by promoting apoptotic (senolytics) or nonapoptotic (senotopics) cell death, while senomorphics suppress SASP production. However, given the dynamic and complex nature of senescence and SASP, extensive testing is needed for any of the compounds to be useful in clinical settings. Additionally, because SASP stimulates tumor-suppressive immune-clearance of senescent cells, a senescence inducing/ pro-senescent therapy is also being investigated in various cancer types including BC (117). Diverse types of agents such as targeted and chemotherapeutic drugs, phytochemicals, and epigenetic modulators are being examined for this specific purpose (117). 
One side effect of suppressing SASP production is that it may cause senescent cells no longer recognizable by the immune system, persist over a long-period of time, eventually interfering with healthy tissue function (118). Targeting specific SASP components with neutralizing antibodies, for example, could help avoid this problem. Likewise, senescent cells, induced by pro-senescence therapies, unless rapidly cleared by the immune system, could essentially accumulate, altering the tumor and immune microenvironment through persistent SASP production. This in the long-run might result in tumor relapse and metastasis (119). Another likely side effect of pro-senescence therapy when administered via systemic route is due to the generation and accumulation of senescent cells in different tissues and organs, which in turn might accelerate the onset and progression of chronic aging-associated disorders such as cardiovascular, neurodegenerative, fibrotic diseases, to name a few $(120,121)$. Some of these detrimental effects of pro-senescent therapies can be overcome by careful selection of the therapeutic agents, choosing appropriate delivery routes, continuous monitoring of the therapy response, and using adjuvant immunotherapy preventing tissue build-up of senescent cells $(118,119,122)$.

\section{TNBC AND CHEMORESISTANCE}

TNBC, lacking expression of the estrogen, progesterone receptors (ER, PR) and amplification and/or overexpression of the Human Epidermal Growth Factor Receptor 2 (HER2), is characterized by high mitotic index, advanced grade and stage, and increased immune cell infiltration. TNBC patients often experience poor prognosis, frequent distant metastases, recurrent disease, and reduced overall survival $(9,10,13)$. TNBCs are further categorized into several molecular subtypes (basal-like: BL1 and BL20, immunomodulatory: IM, mesenchymal: M, mesenchymal stem-like: MSL, luminal androgen receptor: LAR), with each sensitive to specific classes of drugs (8).

Because of extensive heterogeneity and lack of HER2, ER, PR expression, chemotherapy is the most preferred choice of treatment for TNBC patients $(10,123)$. In neoadjuvant setting, chemotherapies used are primarily anthracyclines and taxanes, while in adjuvant setting, much diverse combinations consisting of anthracyclines, taxanes, cyclophosphamide, methotrexate, 5Fluorouracil, gemcitabine, and vinorelbine are prescribed (1012). Despite better initial complete pathological response (pCR) than other BC subtypes, especially in the neoadjuvant setting, emergence of resistance is a common phenomenon responsible for poor clinical outcome in $\operatorname{TNBC}(11,12)$.

There are detailed reviews discussing different modes of chemoresistance in TNBC available $(10,17,19)$. Briefly, these are altered expression of ATP-binding cassette (ABC) transporters and microRNAs, heightened drug metabolism, evasion of apoptosis, enrichment of cancer stem cells and related signaling pathways (especially those associated with embryo development), induction of DNA damage and inflammation, activation of lipid kinase and tyrosine kinase signaling pathways, hypoxia, tumor-suppressive immune environment, and inherent intra and inter-tumoral heterogeneity $(10,17,19)$. Although, each of these are potential therapeutic target, because of their complicated interactions and collaborations, they need to be thoroughly studied before bringing into the clinic. Recent trials have confirmed an urgent need for combination treatment and biomarker-based patient selection strategies to enhance the cancer cell specificity and selectivity and lower systemic toxicity. In this regard, two types of therapeutic interventions, metronomic chemotherapy and polychemotherapy, are particularly noteworthy. The former involves frequent administration of chemotherapeutic drugs below the maximum-tolerated dose (MTD), while the latter utilizes combinations of several drugs. However, none of these has been approved yet (124-127).

In addition to individual molecules or signaling pathways, specific cellular fate that TNBC cells readily adapt to avoid chemotherapy-induced cell death, also contributes to drug resistance and eventual disease recurrence. Notable among these is therapy-induced senescence (TIS) (10). In addition to direct response to chemotherapies, TIS may also be prompted by microenvironmental stressors including hypoxia, nutrient deprivation, and oxidative damage, which in turn alter patterns of chemotherapy response (128-131). There are numerous reports of occurrence of TIS in BC cell lines, including those of TNBC origin by standard genotoxic agents including doxorubicin (132, 133), etoposides (134), irinotecan (132), methotrexate (132), paclitaxel $(132,135)$, cisplatin $(136,137)$, and even with metronomic schedule (138). In clinical setting, Poele et al. was one of the first to report presence of senescent cells in archival samples of breast tumors from patients receiving neoadjuvant chemotherapy (cyclophosphamide, Adriamycin, and 5-fluorouracil). Compared to the $10 \%$ samples from patients who received no treatment prior to surgery, $41 \%$ chemotherapy-treated tumors showed SA- $\beta$-gal-positivity. The authors also found an association between SA- $\beta$-gal staining with low p53 and high p16 staining. Normal tissue sections or normal cells surrounding the tumor sections were completely negative for SA- $\beta$-gal and did not have altered expression of the above-mentioned two tumor suppressor proteins. They concluded that senescence induction is a natural response to chemotherapy treatment in BC and it may play important role in determining treatment outcome (139). Another study that discussed the importance of TIS in disease prognosis and therapy response was by Laine et al., who demonstrated that overexpression of CIP2A (cancerous inhibitor of PP2A), a negative regulator of senescence leads to adverse patient outcome and resistance to senescence-inducing chemotherapy (140). Using genetically engineered model of mouse mammary tumor (MMTV-Wnt1) Jackson et al. established a detrimental association between senescence and chemotherapy response, specifically in the wild-type (WT) p53 background (a key regulator of senescence), possibly through SASP (141). Their data corroborated previous reports indicating a negative association between functional p53 and response to high dose 
chemotherapy in patients with advanced BC $(142,143)$. It also provided an explanation to the fact that majority of basal-like $\mathrm{BC}$ (included into the TNBC subtype) (144) with mutated p53 exhibits complete response to chemotherapy, while the luminal subtype retaining WT p53 is somewhat chemoresistant $(18,145)$. Instead of examining the effect of adjuvant chemotherapy on tumor cells, Sanoff et al. focused on non-malignant cells in BC patients. They discovered a 75\% increase in p16 mRNA levels in peripheral T cells, which was accompanied by a stable increase in the levels of two SASP components VEGF and MCP-1 in patients' plasma. While the majority of patients displayed signs of accelerated molecular aging that sustained until several years after therapy, the response was highly variable. They also discovered that the post-chemotherapy molecular aging is equivalent to $10-15$ years of chronological aging. The authors concluded that such detrimental side effects of chemotherapy is responsible for the long-term systemic toxicity in cancer patients whose magnitude depends on the molecular rather than the chronological age of the individual (146, 147). This was corroborated by another study that implicated SASP components (IL-1 $\alpha$, IL-6, IL-8, CCL2, and CXCL12) in the short and long-term comorbidities of chemotherapies, for example fatigue, cardiac dysfunction, reduced bone volume and density, loss of physical functions and appetite (148).

A handful of studies reported a two-step strategy therapeutically exploiting TIS in TNBC pre-clinical models. The first step involved induction of TIS with chemotherapy or other treatment modalities, while the second step consisted of follow-up treatment with senolytics. For example, Galiana et al. explored the effect of palbociclib-induced TIS, followed by senolysis with nano-encapsulated navitoclax in immunocompetent mouse models of advanced TNBC and discovered tumor growth inhibition and reduced metastasis (29). In another study, TNBC cell lines were successfully inhibited by sequential treatments with senescence-inducing BET domain inhibitor and senolytic navitoclax (149). A discovery-stage biopharmaceutical company Senolytic Therapeutics (STX) is currently developing a diagnostic test SenolT for detecting and monitoring post-therapy (radiation/ chemotherapy) senescent cells in liquid biopsy samples from TNBC patients (https://cordis.europa.eu/project/id/826909). The test is meant to find the association between TIS and TNBC recurrence.

\section{SENESCENCE-INDUCED STEMNESS AND ITS THERAPEUTIC IMPLICATION IN CANCERS INCLUDING TNBC}

Survival of a rare population of tumor cells possessing CSC-like characteristics following chemotherapy is a key contributor of resistance (150-153). In a seminal paper published by Bhola et al., gene expression analysis of matched pair of 17 pre- and post-chemotherapy primary BC biopsies (including TNBC specimens) revealed an enrichment of signatures of CSC and TGF- $\beta$, the cytokine famous for its association with breast stem cells and CSCs in treated samples. They went on to demonstrate a causal association between post-chemotherapy CSC enrichment with TGF- $\beta$ signaling, which upon pharmacological intervention prevented in vivo tumor relapse in pre-clinical modes of TNBC (154). While this study did not demonstrate any connection between TIS and CSC enrichment, the senescence-promoting autocrine/paracrine role of TGF- $\beta$ signaling in aging/aging-related pathologies, particularly in the context of stem cells is already known (155).

Acquisition of stem-like properties following TIS induction is implicated in drug-resistance $(4,5,20)$. For example, Milanovic et al. observed by using GMM models of B-cell lymphoma a substantial upregulation of stem cell signature, activated Wnt signaling pathway and stemness-associated marker expression in chemotherapy-induced senescent population (31). Induction of senescence-associated stemness (SAS) was extended beyond TIS as they detected it in the models of replicative as well as stressinduced senescence. Finally, in blood cancer cell lines and patient samples such SAS induction was found to be correlated with relapse of aggressive tumors (31). In an attempt to find out what triggers SAS, these authors and others discovered the involvement of cell-intrinsic mechanisms such as activation of Wnt signaling $(31,156)$ and epigenetic mechanism (157). However, SASP, particularly its pro-inflammatory cytokine constituents known to cause cellular reprogramming, plasticity, and tissue regeneration $(113,158,159)$, also contributes to SAS induction (160), not only in cell-autonomous fashion, but nonautonomously by interacting with the non-senescent cells in the microenvironment $(4,5,160)$. Specifically for TNBC, very few reports establishing a positive link between SAS and chemoresistance are available. The most noteworthy of these is the work reported by Achuthan et al., in which by using TNBC pre-clinical model the authors demonstrated a causal relationship between TIS and generation of chemoresistant stem-like population (20). Another study with TNBC biopsy samples added an interesting factor, polyploidy to the SAS and chemoresistance connection. The authors found that all tumors that failed to respond to neoadjuvant chemotherapy possessed a significant proportion of senescent cells (161).

In the previous section, we have already discussed the twostep strategy (senogenics, followed by senolytics treatment) for prevention/elimination of chemoresistance and relapse of aggressive, metastatic tumors. Some scientists exploring this approach also presented convincing evidences for the importance of SAS inhibition in this context (31-36). Nevertheless, conveying this observation to the clinic requires careful optimization of the dose and treatment regimen.

\section{EFFECT OF TIS ON THE EFFICACIES OF IMMUNE- AND DDR-DIRECTED THERAPIES IN TNBC}

In recent years, immunotherapy has emerged as one of the most sought-out treatment strategies, capable of producing durable anti-tumor responses. Success of immunotherapy in general, 
depends on the inherent immunogenicity of the tumor. Although, traditionally perceived as an immunologically "cold" type, $\mathrm{BC}$, especially the TNBC subtype, is now being considered curable by immunotherapies (21). In this regard, the immune checkpoint inhibitors (ICI) targeting the negative regulators of T cell activation (cytotoxic $\mathrm{T}$ lymphocyte-associated protein-4/ CTLA-4, programmed cell death protein-1/PD-1, and programmed death-ligand 1/PD-L1), have gained the most attention. In 2019, both US FDA and European Medicines Agency (EMA) granted accelerated approval for use of the anti-PD-L1 antibody atezolizumab with nab-paclitaxel as the first-line treatment for PD-L-1+, unresectable, locally advanced or metastatic TNBC (21). A substantial number of trials exploring efficacies of PD-1 or PD-L1 antibodies against $\mathrm{BC}$ either as monotherapies or in combination with the radiation, chemo, targeted, or other forms of immunotherapies are in progress. Although promising, only a small percentage of TNBC patients experience a durable objective response to ICI regimen. Also, a strong tumor-associated PD-L1 signal does not always faithfully predict the overall survival, prognosis, and response to anti-PD-L-1 therapy in TNBC (21). Recent research has also indicated a detrimental role of aging and inflammation-associated effector $\mathrm{T}$ cell senescence in immunotherapy efficacy. A potential role of senescent $\mathrm{T}$ cellderived SASP in modulation of the tumor microenvironment (TME), although not entirely clear, is suspected [(162) and the references therein].

In early stage, locally advanced or metastatic TNBC patients, chemotherapies when combined with the ICI blockage, produced encouraging anti-tumor response. This was different from the immunosuppressive effects of some chemotherapies (163). The specific effect of pre-ICI chemotherapy on metastatic TNBC was explored in the TONIC trial that included a two-week preconditioning with cyclophosphamide, cisplatin, and doxorubicin prior to anti-PD-1 therapy (164). The short duration of chemotherapy was assumed to be sufficient for enhancing the anti-tumor efficacy of PD-1 blockade by promoting immunogenic death of tumor cells and implementing pro-immunogenic changes in the tumor microenvironment (TME), but inadequate to negatively affect immune cells, especially the $\mathrm{T}$ cells. The overall objective response rate (ORR) was $20 \%$ more than the previous trials, with the highest ORR (35\%) achieved with the doxorubicin induction arm. The TONIC trial clearly highlighted the favorable effect of a chemotherapy induction step prior to ICI therapy in TNBC (164).

An important question is how does TIS fit into the aforementioned benefit of chemotherapy precondition step to the PD-1/PD-L1-based immunotherapies in TNBC? Chemotherapy triggers TIS and subsequent SASP production. The immune modulatory components of SASP promote immune cell infiltration to the tumor, which upon further activation of the immune system clears both senescent and non-senescent cancer cells $(26,120,165)$. This is also supported by the fact that pro-senescent therapies, although capable of prompting tumor growth arrest, are ineffective in causing tumor regression or elimination on their own and require a two-step strategy along with a functional immune system $(118,166)$. Mechanistic details of the sensitizing effects of SASP on ICI-directed therapies although known for cancers of the ovary (24), pancreas (25), and melanoma (26), are yet to be identified for TNBC.

Poly (ADP-ribose) polymerase (PARP) is a DNA damage repair protein which when inhibited in cancers having defective homologous recombination (HR), such as those caused by the Breast Cancer gene BRCA1/2 deficiency, results in synthetic lethality. This is because PARP inhibitor (PARPi) treatment results in accumulation of unrepaired DNA single-strand breaks (SSBs), which during replication and in the absence of functional BRCA1/2 are converted to lethal double-strand breaks (DSBs) (167). Deficiencies in additional HR repair proteins including MRN complex, PALB2, RAD51, RAD54, DSS1, RPA1, NBS1, ATR, ATM, CHK1, CHK2, FANCD2, FANCA, and FANCC are also synthetically lethal with PAPRi (168). Currently, PARPi are recommended for the treatment of TNBC (olaparib and talazoparib) and epithelial ovarian cancers (olaparib, niraparib, and rucaparib) harboring $B R C A 1 / 2$ mutations (22), but their long-term efficacies are variable and independent of the HR status $(23,169,170)$. Although, restoration of $\mathrm{HR}$ and replication fork stalling are the most common mechanisms of PARPi resistance, HR-independent escape strategies are not rare (171). Recent work by Fleury et al. demonstrated that the DDR elicited by PARPi renders a TIS-like state along with production of inflammatory cytokines in both breast and ovarian cancer cells leading to tumor relapse. This was overcome by treatment with senolytic drugs, such as those that inhibit anti-apoptotic BCL-2 and BCL-XL proteins. This work confirmed TIS as a critical contributor of PARPi response and supported the importance of a two-step treatment approach with PARPi and senotherapeutics in breast and ovarian cancer cells (23).

So far, we have presented necessary evidences to convince the readers that TIS plays important roles in the chemo, immune, and DDR-directed therapeutic responses in TNBC. Nevertheless, no clear guideline exists for exploiting TIS for the benefits of patients, which could be attributed to the following factors. 1) TIS is highly dependent on the nature and extent of stress, so no two therapeutic agents will impose exactly the same type of senescence response in tumor cells. 2) There is no single property of senescent cells that can be consistently used for easy detection of TIS in clinical specimens. 3) SASP production is a highly dynamic and context-dependent phenomena. 4) Cell autonomous and non-autonomous effects of SASP on the tumor cells and their microenvironment (TME) depend on the composition of SASP at any given time. 5) Tumor heterogeneity, history of inflammation, aging among others influence the overall response of the tumor and TME to TIS. 6) Senescence in non-tumor cells triggered by systemic therapies could potentially contribute not only to the drug toxicity, but also to the reduction in therapeutic benefit. We believe that some of these complexities can be overcome by generating a broadspectrum multi-omics-based predictive TIS-signature from 
TNBC cells (irrespective of the type and dose of the therapeutic agent or its exposure time) and utilizing it for making therapeutic decisions. Because, SASP is responsible for most of the detrimental effects of TIS, we speculate that senomorphics (agents that interfere with SASP), rather than senolytics in combination with appropriate immunotherapeutic drugs will be superior in generating beneficial therapeutic response in TNBC.

\section{TACKLING TIS IN TNBC FROM THE EVOLUTION STANDPOINT}

Although, immunotherapy and DDR-directed therapies are gaining acceptance for TNBC treatment, due to the low number of patients benefitting from both therapeutic strategies along with the scarcity of predictive biomarkers for patient selection, combination chemotherapies continue to be the standard care for TNBC patients. Compared to other BC subtypes, newly diagnosed TNBCs are more sensitive to conventional chemotherapies. However, those patients who fail to achieve complete pathologic response/pCR are at high risk of relapse and progressively poorer responses toward second-, third-, and fourth-line treatment $(7,11$, $12,17)$. According to the principles of evolutionary biology, this is caused by the "competitive release" of already present, yet rare resistant clones (38). In this respect, the overall poor prognosis and survival of TNBC patients can be attributed to evolution. Alternative therapeutic strategies employing the principles of dynamic tumor evolution (known as the adaptive therapy), could certainly be crucial for suppression of drug-resistant tumor cell populations and long-term TNBC control.

Owing to their inherent heterogeneity and abilities to interact with the microenvironment in a spatio-temporal and non-linear fashion, cancers can be viewed as an open complex adaptive systems, to which perturbations (such as anti-cancer drug treatment) are expected to result in unanticipated consequences (38). However, even such unpredictable systems can effectively be controlled if appropriate therapeutic strategies are designed on the basis of their dynamic nature (38). One such strategy should focus on exploiting the phenotypic cost of resistance. A popular example is the fitness differences of the multidrug-resistant $\mathrm{ABC}$ transporter-expressing tumor cell population in presence and absence of drug. The strategy that exploited the lower fitness of resistant cells without the drug involved alternative treatment cycles of chemotherapy and fake drug ("ersatzdroges"), forcing the resistant cells to spend significant amount of energy in pumping the drug out rather than growing and invading (172). A similar approach can be proposed for inhibiting TNBC cells that have emerged as chemoresistant through TIS. Senescence, both in oncogene and chemotherapy-induced settings, is associated with activation of the unfolded protein response (UPR) pathway $(173,174)$. This could somewhat be attributed to the excessive ER stress due to increased demand of synthesis, maturation, and secretion of the SASP-associated proteins (174). Others associate this with increased oxidative stress or activation of autophagy in senescent cells (174). Nevertheless, the heightened dependency on the UPR pathway could in theory render the senescent TNBC cells vulnerable to pharmacological dysregulation of ER stress $(173,174)$. Reliance of the senescent cells on certain metabolic pathways (175), could similarly be pharmacologically pursued as an adaptive therapeutic strategy.

Secondly, to prevent chemoresistance in TNBC through TIS, the famous "first strike-second strike" strategy put forward by Gatenby et al. (176) can also be adapted. The premise of this approach is that strategic application of drugs or drug combinations that are otherwise not curative in appropriate sequences would mimic dynamics of background extinction of

A

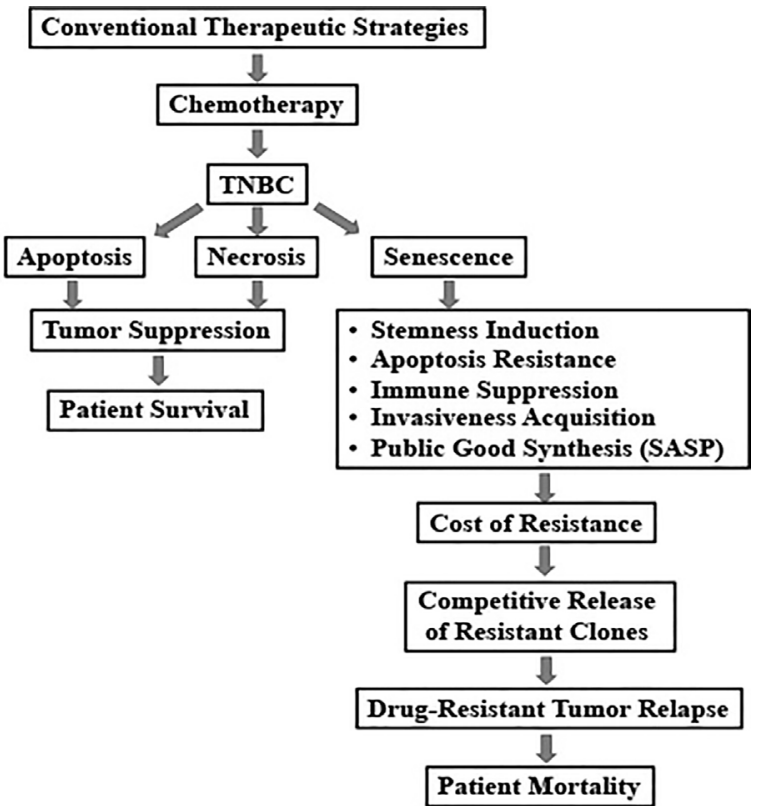

B Conventional Therapeutic Strategies
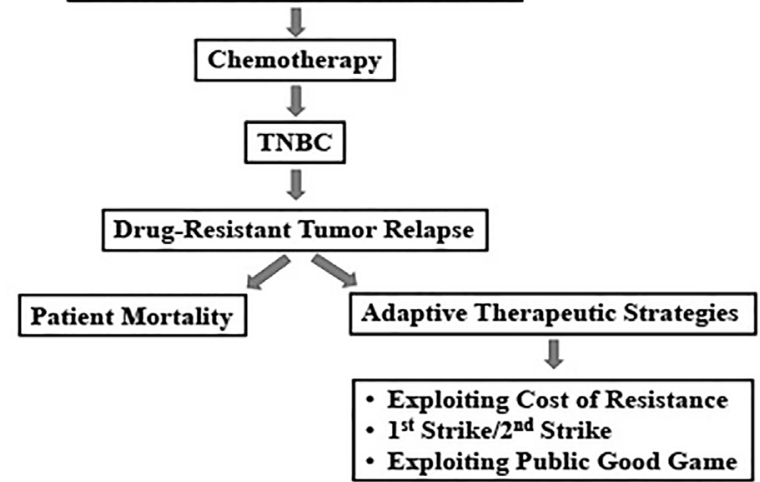

$\Downarrow$

Tumor Suppression

$\sqrt{1}$

Patient Survival

FIGURE 2 | Schematic representation of conventional and adaptive treatment strategies and their outcomes in triple negative breast cancers. (A) Relapse of drug-resistant tumors due to conventional chemotherapy-induced senescence in TNBC patients. (B) Adaptive therapeutic strategies to combat chemotherapy-induced senescence in TNBC. 
many large, diverse, and geographically scattered species (comparable to heterogeneous and disseminated cancer cells). The first strike is meant to reduce the population size and diversity of the tumor, with the following strikes causing ecoevolutionary distresses pushing the vulnerable small populations of surviving cells to extinction threshold (176). In case of TNBC, the first strike could be constituted of low-dose chemotherapy, immediately followed by immune predation of senescent cells, then followed by cancer stem cell-targeting therapy. While, none of these are capable of destroying the tumor on their own, when applied in right order, would force the small, comparatively homogeneous tumor cell populations to be exterminated. With a similar strategy proven to cure pediatric ALL, we are hopeful that it would be beneficial for long-term TNBC control.

Our final recommendation is to disrupt the dynamics of "public good games" (PGGs) in TNBC played by the senescent and non-senescent tumor and microenvironmental cells. Public goods, in general are the secretory products (growth factors, angiogenic factors, metabolic intermediates, etc.) of certain cell populations that are beneficial for the tumor as whole. In a heterogeneous tumor ecosystem, public goods producers exist in dynamic equilibrium with the non-producers (cheaters and freeriders) $(177,178)$. While, modeling the PGGs is not an easy task (179), the interdependency between the producers and freeriders is an exploitable feature for tumor control. In their seminal work, Archetti et al., by using experimental model of neuroendocrine pancreatic cancer, studied the dynamics of cooperation and defection between the insulin-like growth factor (IGF)-II producers and free-riders (180). In a mixed population, the producers exist in a stable equilibrium with the free-riders, which can otherwise be altered by modulating the amount of growth factor. The authors proposed that modification of the dynamics of growth factor production could be a way of stable tumor control. Such observation is highly relevant for TIS-adapted TNBC cells, as SASP production by the senescent cells is crucial for the establishment and maintenance of stem-like, immune-suppressive, drug-resistant phenotypes (68). Senomorphics, by restricting the SASP production, in principle would be useful for reversion of chemoresistance. Similar approach has been recognized as an effective therapeutic strategy against aging and age-related disorders and is under intense investigation (181).

\section{CONCLUSION}

TNBC needs better therapeutic intervention. Even with the recent availability of the immune- and DDR-directed therapies, chemotherapy remains in the frontline of treatment choices for TNBC patients. One of the main reasons of the poor clinical outcome in TNBC patients is emergence of chemotherapy resistance. Herein, we have discussed a cellular fate, called senescence and its involvement in oncogenesis and chemoresistance, particularly in the context of induction of stemness. Finally, we have reasoned how evolution can be the major driving force of emergence of resistance and accordingly proposed three adaptive strategies to confront TIS-mediated chemoresistance in TNBC (Figure 2). Although, the theoretical support on TIS as an evolutionary fitter strategy is yet to be established, based on its recognition as a critical modulator of treatment outcome in cancer, we predict that soon it will receive its due attention from evolutionary biologists.

\section{AUTHOR CONTRIBUTIONS}

AC conceptualized the idea. AC, SC, and GC wrote the manuscript. AC, SC, and RB complied the information. All the authors contributed to the article and approved the submitted version.

\section{ACKNOWLEDGMENTS}

The authors would like toacknowledge the Shiv Nadar University for providing financial support for paying the open access fee.

\section{REFERENCES}

1. Shay JW, Wright WE. Hayflick, His Limit, and Cellular Ageing. Nat Rev Mol Cell Biol (2000) 1(1):72-6. doi: 10.1038/35036093

2. Hayflick L, Moorhead PS. The Serial Cultivation of Human Diploid Cell Strains. Exp Cell Res (1961) 25:585-621. doi: 10.1016/0014-4827(61)90192-6

3. He S, Sharpless NE. Senescence in Health and Disease. Cell (2017) 169 (6):1000-11. doi: 10.1016/j.cell.2017.05.015

4. Triana-Martínez F, Loza MI, Domínguez E. Beyond Tumor Suppression: Senescence in Cancer Stemness and Tumor Dormancy. Cells (2020) 9(2). doi: $10.3390 /$ cells 9020346

5. Dou Z, Berger SL. Senescence Elicits Stemness: A Surprising Mechanism for Cancer Relapse. Cell Metab (2018) 27(4):710-1. doi: 10.1016/j.cmet.2018.03.009

6. Smigiel JM, Taylor SE, Bryson BL, Tamagno I, Polak K, Jackson MW. Cellular Plasticity and Metastasis in Breast Cancer: A Pre- and PostMalignant Problem. J Cancer Metastasis Treat (2019) 5. doi: 10.20517/23944722.2019 .26

7. Mongiardi MP, Pellegrini M, Pallini R, Levi A, Falchetti ML. Cancer Response to Therapy-Induced Senescence: A Matter of Dose and Timing. Cancers (Basel) (2021) 13(3). doi: 10.3390/cancers13030484

8. Lehmann JA, Bauer JA, Chen X, Sanders ME, Chakravarthy AB, Shyr Y, et al. Identification of Human Triple-Negative Breast Cancer Subtypes and Preclinical Models for Selection of Targeted Therapies. J Clin Invest (2011) 121(7):2750-67. doi: 10.1172/JCI45014

9. Schneider BP, Winer EP, Foulkes WD, Garber J, Perou CM, Richardson A, et al. Triple-Negative Breast Cancer: Risk Factors to Potential Targets. Clin Cancer Res (2008) 14(24):8010-8. doi: 10.1158/1078-0432.CCR-08-1208

10. O'Reilly EA, Gubbins L, Sharma S, Tully R, Guang MH, Weiner-Gorzel K, et al. The Fate of Chemoresistance in Triple Negative Breast Cancer (TNBC). BBA Clin (2015) 3:257-75. doi: 10.1016/j.bbacli.2015.03.003

11. Chacón RD, Costanzo MV. Triple-Negative Breast Cancer. Breast Cancer Res (2010) 12(Suppl 2):S3. doi: 10.1186/bcr2574

12. Hudis CA, Gianni L. Triple-Negative Breast Cancer: An Unmet Medical Need. Oncologist (2011) 16(Suppl 1):1-11. doi: 10.1634/theoncologist.2011-S1-01 
13. Dent R, Trudeau M, Pritchard KI, Hanna WM, Kahn HK, Sawka CA, et al. Triple-Negative Breast Cancer: Clinical Features and Patterns of Recurrence. Clin Cancer Res (2007) 13(15 Pt 1):4429-34. doi: 10.1158/1078-0432.CCR06-3045

14. Diana A, Franzese E, Centonze S, Carlino F, Della Corte CM, Ventriglia J, et al. Triple-Negative Breast Cancers: Systematic Review of the Literature on Molecular and Clinical Features With a Focus on Treatment With Innovative Drugs. Curr Oncol Rep (2018) 20(10):76. doi: 10.1007/s11912018-0726-6

15. Bergin ART, Loi S. Triple-Negative Breast Cancer: Recent Treatment Advances. F1000Res (2019) 8. doi: 10.12688/f1000research.18888.1

16. Lebert JM, Lester R, Powell E, Seal M, McCarthy J. Advances in the Systemic Treatment of Triple-Negative Breast Cancer. Curr Oncol (2018) 25(Suppl 1): S142-S150. doi: $10.3747 /$ co.25.3954

17. Nedeljkovic M, Damjanovic A. Mechanisms of Chemotherapy Resistance in Triple-Negative Breast Cancer-How We Can Rise to the Challenge. Cells (2019) 8. doi: 10.3390/cells8090957

18. Carey LA, Dees EC, Sawyer L, Gatti L, Moore DT, Collichio F, et al. The Triple Negative Paradox: Primary Tumor Chemosensitivity of Breast Cancer Subtypes. Clin Cancer Res (2007) 13(8):2329-34. doi: 10.1158/10780432.CCR-06-1109

19. Wein L, Loi S. Mechanisms of Resistance of Chemotherapy in Early-Stage Triple Negative Breast Cancer (TNBC). Breast (2017) 34 Suppl 1:S27-s30. doi: 10.1016/j.breast.2017.06.023

20. Achuthan S, Santhoshkumar TR, Prabhakar J, Nair SA, Pillai MR. DrugInduced Senescence Generates Chemoresistant Stemlike Cells With Low Reactive Oxygen Species. J Biol Chem (2011) 286:37813-29. doi: 10.1074/ jbc.M110.200675

21. Thomas R, Al-Khadairi G, Decock J. Immune Checkpoint Inhibitors in Triple Negative Breast Cancer Treatment: Promising Future Prospects. Front Oncol (2020) 10:600573. doi: 10.3389/fonc.2020.600573

22. Mateo J, Lord CJ, Serra V, Tutt A, Balmaña J. A Decade of Clinical Development of PARP Inhibitors in Perspective. Ann Oncol (2019) 30 (9):1437-47. doi: 10.1093/annonc/mdz192

23. Fleury H, Malaquin N, Tu V, Gilbert S, Martinez A, Olivier MA, et al. Exploiting Interconnected Synthetic Lethal Interactions Between PARP Inhibition and Cancer Cell Reversible Senescence. Nat Commun (2019) 10 (1):2556. doi: 10.1038/s41467-019-10460-1

24. Hao X, Zhao B, Zhou W, Liu H, Fukumoto T, Gabrilovich D, et al. Sensitization of Ovarian Tumor to Immune Checkpoint Blockade by Boosting Senescence-Associated Secretory Phenotype. iScience (2021) 24 (1):102016. doi: $10.1016 /$ j.isci.2020.102016

25. Ruscetti M, Morris JPT, Mezzadra R, Russell J, Leibold J, Romesser PB, et al. Senescence-Induced Vascular Remodeling Creates Therapeutic Vulnerabilities in Pancreas Cancer. Cell (2020) 181(2):424-41.e21. doi: 10.1016/j.cell.2020.03.008

26. Vilgelm AE, Johnson CA, Prasad N, Yang J, Chen S-C, Ayers GD, et al. Connecting the Dots: Therapy-Induced Senescence and a TumorSuppressive Immune Microenvironment. J Natl Cancer Inst (2016) 108(6). doi: $10.1093 /$ jnci/djv406

27. Dörr JR, Yu Y, Milanovic M, Beuster G, Zasada C, Däbritz JHM, et al. Synthetic Lethal Metabolic Targeting of Cellular Senescence in Cancer Therapy. Nature (2013) 501:421-5. doi: 10.1038/nature12437

28. Muñoz-Espín D, Rovira M, Galiana I, Giménez C, Lozano-Torres B, PaezRibes M, et al. A Versatile Drug Delivery System Targeting Senescent Cells. EMBO Mol Med (2018) 10(9). doi: 10.15252/emmm.201809355

29. Galiana I, Lozano-Torres B, Sancho M, Alfonso M, Bernardos A, Bisbal V, et al. Preclinical Antitumor Efficacy of Senescence-Inducing Chemotherapy Combined With a Nanosenolytic. J Control Release (2020) 323:624-34. doi: 10.1016/j.jconrel.2020.04.045

30. Triana-Martínez F, Picallos-Rabina P, Da Silva-Álvarez S, Pietrocola F, Llanos S, Rodilla V, et al. Identification and Characterization of Cardiac Glycosides as Senolytic Compounds. Nat Commun (2019) 10(1):4731. doi: 10.1038/s41467-019-12888-x

31. Milanovic M, Fan DNY, Belenki D, Däbritz JHM, Zhao Z, Yu Y, et al. Senescence-Associated Reprogramming Promotes Cancer Stemness. Nature (2018) 553(7686):96-100. doi: 10.1038/nature25167
32. Castro-Vega LJ, Jouravleva K, Ortiz-Montero P, Liu WY, Galeano JL, Romero $\mathrm{M}$, et al. The Senescent Microenvironment Promotes the Emergence of Heterogeneous Cancer Stem-Like Cells. Carcinogenesis (2015) 36(10):1180-92. doi: 10.1093/carcin/bgv101

33. Canino C, Mori F, Cambria A, Diamantini A, Germoni S, Alessandrini G, et al. SASP Mediates Chemoresistance and Tumor-Initiating-Activity of Mesothelioma Cells. Oncogene (2012) 31(26):3148-63. doi: 10.1038/ onc.2011.485

34. Yang L, Fang J, Chen J. Tumor Cell Senescence Response Produces Aggressive Variants. Cell Death Discovery (2017) 3. doi: 10.1038/ cddiscovery.2017.49

35. Kim YH, Choi YW, Lee J, Soh EY, Kim JH, Park TJ. Senescent Tumor Cells Lead the Collective Invasion in Thyroid Cancer. Nat Commun (2017) 8:15208. doi: $10.1038 /$ ncomms 15208

36. Lee HG, Kim JH, Sun W, Chi SG, Choi W, Lee KJ. Senescent Tumor Cells Building Three-Dimensional Tumor Clusters. Sci Rep (2018) 8(1):10503. doi: 10.1038/s41598-018-28963-0

37. Saleh T, Carpenter VJ, Tyutyunyk-Massey L, Murray G, Leverson JD, Souers AJ, et al. Clearance of Therapy-Induced Senescent Tumor Cells by the Senolytic ABT-263 Via Interference With BCL-X(L) -BAX Interaction. Mol Oncol (2020) 14(10):2504-19. doi: 10.1002/1878-0261.12761

38. Enriquez-Navas PM, Wojtkowiak JW, Gatenby RA. Application of Evolutionary Principles to Cancer Therapy. Cancer Res (2015) 75 (22):4675-80. doi: 10.1158/0008-5472.CAN-15-1337

39. Axtell RC, Arends JJ. Ecology and Management of Arthropod Pests of Poultry. Аnnu Rev Entomol (1990) 35:101-26. doi: 10.1146/annurev.en. 35.010190 .000533

40. Renton M, Busi R, Neve P, Thornby D, Vila-Aiub M. Herbicide Resistance Modelling: Past, Present and Future. Pest Manag Sci (2014) 70(9):1394-404. doi: 10.1002/ps.3773

41. Salama R, Sadaie M, Hoare M, Narita M. Cellular Senescence and its Effector Programs. Genes Dev (2014) 28:99-114. doi: 10.1101/gad.235184.113

42. Ogrodnik M, Salmonowicz H, Jurk D, Passos JF. Expansion and Cell-Cycle Arrest: Common Denominators of Cellular Senescence. Trends Biochem Sci (2019) 44(12):996-1008. doi: 10.1016/j.tibs.2019.06.011

43. Dodig S, Čepelak I, Pavić I. Hallmarks of Senescence and Aging. Biochem Med (Zagreb) (2019) 29(3):030501. doi: 10.11613/BM.2019.030501

44. Hernandez-Segura A, Nehme J, Demaria M. Hallmarks of Cellular Senescence. Trends Cell Biol (2018) 28(6):436-53. doi: 10.1016/ j.tcb.2018.02.001

45. Erenpreisa J, Salmina K, Cragg M. Accelerated Senescence of Cancer Stem Cells: A Failure to Thrive or a Route to Survival? In: J Dorszewska, W Kozubski, editors. Senescence-Physiology or Pathology. UK: Intech (2017). doi: 10.5772/intechopen.68582

46. Bent EH, Gilbert LA, Hemann MT. A Senescence Secretory Switch Mediated by PI3K/AKT/mTOR Activation Controls Chemoprotective Endothelial Secretory Responses. Genes Dev (2016) 30(16):1811-21. doi: 10.1101/ gad.284851.116

47. Lloyd AC. The Regulation of Cell Size. Cell (2013) 154(6):1194-205. doi: 10.1016/j.cell.2013.08.053

48. Blagosklonny MV. Cell Cycle Arrest is Not Yet Senescence, Which is Not Just Cell Cycle Arrest: Terminology for TOR-driven Aging. Aging (Albany NY) (2012) 4(3):159-65. doi: 10.18632/aging.100443

49. Loffredo FS, Steinhauser ML, Jay SM, Gannon J, Pancoast JR, Yalamanchi P, et al. Growth Differentiation Factor 11 is a Circulating Factor That Reverses Age-Related Cardiac Hypertrophy. Cell (2013) 153(4):828-39. doi: 10.1016/ j.cell.2013.04.015

50. Hwang ES, Yoon G, Kang HT. A Comparative Analysis of the Cell Biology of Senescence and Aging. Cell Mol Life Sci (2009) 66(15):2503-24. doi: 10.1007/ s00018-009-0034-2

51. Druelle C, Drullion C, Deslé J, Martin N, Saas L, Cormenier J, et al. Atf6 $\alpha$ Regulates Morphological Changes Associated With Senescence in Human Fibroblasts. Oncotarget (2016) 7(42):67699-715. doi: 10.18632/ oncotarget. 11505

52. Cormenier J, Martin N, Deslé J, Salazar-Cardozo C, Pourtier A, Abbadie C, et al. The Atff $\alpha$ Arm of the Unfolded Protein Response Mediates Replicative Senescence in Human Fibroblasts Through a COX2/prostaglandin E(2) 
Intracrine Pathway. Mech Ageing Dev (2018) 170:82-91. doi: 10.1016/ j.mad.2017.08.003

53. Tam AB, Mercado EL, Hoffmann A, Niwa M. ER Stress Activates NF-kb by Integrating Functions of Basal IKK Activity, IRE1 and PERK. PloS One (2012) 7(10):e45078. doi: 10.1371/journal.pone.0045078

54. Rao J, Yue S, Fu Y, Zhu J, Wang X, Busuttil RW, et al. ATF6 Mediates a ProInflammatory Synergy Between ER Stress and TLR Activation in the Pathogenesis of Liver Ischemia-Reperfusion Injury. Am J Transplant (2014) 14(7):1552-61. doi: 10.1111/ajt.12711

55. Wang M, Kaufman RJ. The Impact of the Endoplasmic Reticulum ProteinFolding Environment on Cancer Development. Nat Rev Cancer (2014) 14 (9):581-97. doi: $10.1038 / \mathrm{nrc} 3800$

56. Ohno-Iwashita $Y$, Shimada $Y$, Hayashi M, Inomata M. Plasma Membrane Microdomains in Aging and Disease. Geriatr Gerontol Int (2010) 10(Suppl 1): S41-52. doi: 10.1111/j.1447-0594.2010.00600.x

57. Dasari A, Bartholomew JN, Volonte D, Galbiati F. Oxidative Stress Induces Premature Senescence by Stimulating Caveolin-1 Gene Transcription Through p38 Mitogen-Activated Protein Kinase/Sp1-mediated Activation of Two GC-rich Promoter Elements. Cancer Res (2006) 66(22):10805-14. doi: 10.1158/0008-5472.CAN-06-1236

58. de Mera-Rodríguez JA, Álvarez-Hernán G, Gañán Y, Martín-Partido G, Rodríguez-León J, Francisco-Morcillo J. Is Senescence-Associated $\beta$ Galactosidase a Reliable In Vivo Marker of Cellular Senescence During Embryonic Development? Front Cell Dev Biol (2021) 9:623175. doi: 10.3389/ fcell.2021.623175

59. Kurz DJ, Decary S, Hong Y, Erusalimsky JD. Senescence-Associated $\beta$ Galactosidase Reflects an Increase in Lysosomal Mass During Replicative Ageing of Human Endothelial Cells. J Cell Sci (2000) 113:3613-22. doi: $10.1242 /$ jcs.113.20.3613

60. Tai H, Wang Z, Gong H, Han X, Zhou J, Wang X, et al. Autophagy Impairment With Lysosomal and Mitochondrial Dysfunction is an Important Characteristic of Oxidative Stress-Induced Senescence. Autophagy (2017) 13(1):99-113. doi: 10.1080/15548627.2016.1247143

61. Passos JF, Saretzki G, Ahmed S, Nelson G, Richter T, Peters H, et al. Mitochondrial Dysfunction Accounts for the Stochastic Heterogeneity in Telomere-Dependent Senescence. PloS Biol (2007) 5(5):e110. doi: 10.1371/ journal.pbio.0050110

62. Studencka M, Schaber J. Senoptosis: non-Lethal DNA Cleavage as a Route to Deep Senescence. Oncotarget (2017) 8(19):30656-71. doi: 10.18632/ oncotarget. 15693

63. Sadaie M, Salama R, Carroll T, Tomimatsu K, Chandra T, Young AR, et al. Redistribution of the Lamin B1 Genomic Binding Profile Affects Rearrangement of Heterochromatic Domains and SAHF Formation During Senescence. Genes Dev (2013) 27(16):1800-8. doi: 10.1101/ gad.217281.113

64. Ivanov A, Pawlikowski J, Manoharan I, van Tuyn J, Nelson DM, Rai TS, et al. Lysosome-Mediated Processing of Chromatin in Senescence. J Cell Biol (2013) 202(1):129-43. doi: 10.1083/jcb.201212110

65. Chandra T, Kirschner K. Chromosome Organisation During Ageing and Senescence. Curr Opin Cell Biol (2016) 40:161-7. doi: 10.1016/ j.ceb.2016.03.020

66. Hernandez-Segura A, de Jong TV, Melov S, Guryev V, Campisi J, Demaria M. Unmasking Transcriptional Heterogeneity in Senescent Cells. Curr Biol (2017) 27(17):2652-2660.e4. doi: 10.1016/j.cub.2017.07.033

67. Yosef R, Pilpel N, Tokarsky-Amiel R, Biran A, Ovadya Y, Cohen S, et al. Directed Elimination of Senescent Cells by Inhibition of BCL-W and BCLXL. Nat Commun (2016) 7. doi: 10.1038/ncomms11190

68. Coppe J, Desprez P, Krtolica A, Campis J. The Senescence-Associated Secretory Phenotype: The Dark Side of Tumor Suppression. Annu Rev Pathol (2010) 5:99-118. doi: 10.1146/annurev-pathol-121808-102144

69. Demaria M, Ohtani N, Youssef SA, Rodier F, Toussaint W, Mitchell JR, et al. An Essential Role for Senescent Cells in Optimal Wound Healing Through Secretion of PDGF-AA. Dev Cell (2014) 31(6):722-33. doi: 10.1016/ j.devcel.2014.11.012

70. Coppé JP, Patil CK, Rodier F, Sun Y, Muñoz DP, Goldstein J, et al. Senescence-Associated Secretory Phenotypes Reveal Cell-Nonautonomous Functions of Oncogenic RAS and the p53 Tumor Suppressor. PloS Biol (2008) 6(12):2853-68. doi: 10.1371/journal.pbio.0060301
71. Misawa T, Tanaka Y, Okada R, Takahashi A. Biology of Extracellular Vesicles Secreted From Senescent Cells as Senescence-Associated Secretory Phenotype Factors. Geriatr Gerontol Int (2020) 20(6):539-46. doi: 10.1111/ ggi.13928

72. Prata L, Ovsyannikova IG, Tchkonia T, Kirkland JL. Senescent Cell Clearance by the Immune System: Emerging Therapeutic Opportunities. Semin Immunol (2018) 40:101275. doi: 10.1016/j.smim.2019.04.003

73. Kirkland JL, Tchkonia T. Cellular Senescence: A Translational Perspective. EBioMedicine (2017) 21:21-8. doi: 10.1016/j.ebiom.2017.04.013

74. Turner VM, Mabbott NA. Influence of Ageing on the Microarchitecture of the Spleen and Lymph Nodes. Biogerontology (2017) 18(5):723-38. doi: 10.1007/s10522-017-9707-7

75. Pang WW, Price EA, Sahoo D, Beerman I, Maloney WJ, Rossi DJ, et al. Human Bone Marrow Hematopoietic Stem Cells are Increased in Frequency and Myeloid-Biased With Age. Proc Natl Acad Sci USA (2011) 108p (50):20012-7. doi: 10.1073/pnas.1116110108

76. Kovtonyuk LV, Fritsch K, Feng X, Manz MG, Takizawa H. Inflamm-Aging of Hematopoiesis, Hematopoietic Stem Cells, and the Bone Marrow Microenvironment. Front Immunol (2016) 7:502. doi: 10.3389/ fimmu.2016.00502

77. Akbar AN, Henson SM, Lanna A. Senescence of T Lymphocytes: Implications for Enhancing Human Immunity. Trends Immunol (2016) 37(12):866-76. doi: 10.1016/j.it.2016.09.002

78. Lynch HE, Goldberg GL, Chidgey A, Van den Brink MR, Boyd R, Sempowski GD. Thymic Involution and Immune Reconstitution. Trends Immunol (2009) 30(7):366-73. doi: 10.1016/j.it.2009.04.003

79. Solana R, Tarazona R, Gayoso I, Lesur O, Dupuis G, Fulop T, et al. Innate Immunosenescence: Effect of Aging on Cells and Receptors of the Innate Immune System in Humans. Semin Immunol (2012) 24(5):331-41. doi: 10.1016/j.smim.2012.04.008

80. Gewirtz DA. Autophagy and Senescence: A Partnership in Search of Definition. Autophagy (2013) 9(5):808-12. doi: 10.4161/auto.23922

81. Kang C, Elledge SJ. How Autophagy Both Activates and Inhibits Cellular Senescence. Autophagy (2016) 12(5):898-9. doi: 10.1080/15548627. 2015.1121361

82. Gerland LM, Peyrol S, Lallemand C, Branche R, Magaud JP, Ffrench M. Association of Increased Autophagic Inclusions Labeled for BetaGalactosidase With Fibroblastic Aging. Exp Gerontol (2003) 38(8):887-95. doi: 10.1016/S0531-5565(03)00132-3

83. Patschan S, Chen J, Polotskaia A, Mendelev N, Cheng J, Patschan D, et al. Lipid Mediators of Autophagy in Stress-Induced Premature Senescence of Endothelial Cells. Am J Physiol Heart Circ Physiol (2008) 294(3):H1119-29. doi: 10.1152/ajpheart.00713.2007

84. Li L, Zhu YQ, Jiang L, Peng W. Increased Autophagic Activity in Senescent Human Dental Pulp Cells. Int Endod J (2012) 45(12):1074-9. doi: 10.1111/ j.1365-2591.2012.02064.x

85. Sasaki M, Miyakoshi M, Sato Y, Nakanuma Y. Autophagy may Precede Cellular Senescence of Bile Ductular Cells in Ductular Reaction in Primary Biliary Cirrhosis. Dig Dis Sci (2012) 57(3):660-6. doi: 10.1007/s10620-0111929-y

86. Sasaki M, Miyakoshi M, Sato Y, Nakanuma Y. Autophagy Mediates the Process of Cellular Senescence Characterizing Bile Duct Damages in Primary Biliary Cirrhosis. Lab Invest (2010) 90(6):835-43. doi: 10.1038/ labinvest.2010.56

87. Gosselin K, Deruy E, Martien S, Vercamer C, Bouali F, Dujardin T, et al. Senescent Keratinocytes Die by Autophagic Programmed Cell Death. Am J Pathol (2009) 174(2):423-35. doi: 10.2353/ajpath.2009.080332

88. Deruy E, Gosselin K, Vercamer C, Martien S, Bouali F, Slomianny C, et al. MnSOD Upregulation Induces Autophagic Programmed Cell Death in Senescent Keratinocytes. PloS One (2010) 5(9):e12712. doi: 10.1371/ journal.pone. 0012712

89. Young AR, Narita M, Ferreira M, Kirschner K, Sadaie M, Darot JF, et al. Autophagy Mediates the Mitotic Senescence Transition. Genes Dev (2009) 23(7):798-803. doi: 10.1101/gad.519709

90. Goehe RW, Di X, Sharma K, Bristol ML, Henderson SC, Valerie K, et al. The Autophagy-Senescence Connection in Chemotherapy: Must Tumor Cells (Self) Eat Before They Sleep? J Pharmacol Exp Ther (2012) 343(3):763-78. doi: 10.1124/jpet.112.197590 
91. Kang HT, Lee KB, Kim SY, Choi HR, Park SC. Autophagy Impairment Induces Premature Senescence in Primary Human Fibroblasts. PloS One (2011) 6(8):e23367. doi: 10.1371/journal.pone.0023367

92. Wang W, Zhang B, Mani AM, Wu Z, Fan Y, Li W, et al. Survivin Inhibitors Mitigate Chemotherapeutic Resistance in Breast Cancer Cells by Suppressing Genotoxic Nuclear Factor-kb Activation. J Pharmacol Exp Ther (2018) 366(1):184-93. doi: 10.1124/jpet.118.249151

93. Drullion C, Trégoat C, Lagarde V, Tan S, Gioia R, Priault M, et al. Apoptosis and Autophagy Have Opposite Roles on Imatinib-Induced K562 Leukemia Cell Senescence. Cell Death Dis (2012) 3(8):e373. doi: 10.1038/ cddis. 2012.111

94. Hoare M, Narita M. The Power Behind the Throne: Senescence and the Hallmarks of Cancer. Annu Rev Cancer Biol (2018) 2(1):175-94. doi: 10.1146/annurev-cancerbio-030617-050352

95. Cuollo L, Antonangeli F, Santoni A, Soriani A. The Senescence-Associated Secretory Phenotype (SASP) in the Challenging Future of Cancer Therapy and Age-Related Diseases. Biol (Basel) (2020) 9(12). doi: 10.3390/ biology9120485

96. Flatt T, Partridge L. Horizons in the Evolution of Aging. BMC Biol (2018) 16 (1):93. doi: 10.1186/s12915-018-0562-z

97. Campisi J. Aging, Cellular Senescence, and Cancer. Annu Rev Physiol (2013) 75(1):685-705. doi: 10.1146/annurev-physiol-030212-183653

98. Carnes BA, Olshansky SJ. Evolutionary Perspectives on Human Senescence. Population Dev Rev (1993) 19(4):793-806. doi: 10.2307/2938414

99. Finkel T, Serrano M, Blasco MA. The Common Biology of Cancer and Ageing. Nature (2007) 448(7155):767-74. doi: 10.1038/nature05985

100. Mooi WJ, Peeper DS. Oncogene-Induced Cell Senescence-Halting on the Road to Cancer. N Engl J Med (2006) 355(10):1037-46. doi: 10.1056/ NEJMra062285

101. Serrano M, Lin AW, McCurrach ME, Beach D, Lowe SW. Oncogenic Ras Provokes Premature Cell Senescence Associated With Accumulation of p53 and P16ink4a. Cell (1997) 88:593-602. doi: 10.1016/S0092-8674(00)81902-9

102. Sarkisian CJ, Keister BA, Stairs DB, Boxer RB, Moody SE, Chodosh LA. Dose-Dependent Oncogene-Induced Senescence In Vivo and its Evasion During Mammary Tumorigenesis. Nat Cell Biol (2007) 9(5):493-505. doi: 10.1038/ncb1567

103. Liu XL, Ding J, Meng LH. Oncogene-Induced Senescence: A Double Edged Sword in Cancer. Acta Pharmacol Sin (2018) 39(10):1553-8. doi: 10.1038/ aps.2017.198

104. Guerra C, Mijimolle N, Dhawahir A, Dubus P, Barradas M, Serrano M, et al. Tumor Induction by an Endogenous K-ras Oncogene is Highly Dependent on Cellular Context. Cancer Cell (2003) 4(2):111-20. doi: 10.1016/S15356108(03)00191-0

105. Terzi MY, Izmirli M, Gogebakan B. The Cell Fate: Senescence or Quiescence. Mol Biol Rep (2016) 43(11):1213-20. doi: 10.1007/s11033-016-4065-0

106. Rao SG, Jackson JG. Sasp: Tumor Suppressor or Promoter? Yes! Trends Cancer (2016) 2(11):676-87. doi: 10.1016/j.trecan.2016.10.001

107. Acosta JC, Banito A, Wuestefeld T, Georgilis A, Janich P, Morton JP, et al. A Complex Secretory Program Orchestrated by the Inflammasome Controls Paracrine Senescence. Nat Cell Biol (2013) 15(8):978-90. doi: 10.1038/ncb2784

108. Iannello A, Thompson TW, Ardolino M, Lowe SW, Raulet DH. p53dependent Chemokine Production by Senescent Tumor Cells Supports NKG2D-dependent Tumor Elimination by Natural Killer Cells. J Exp Med (2013) 210(10):2057-69. doi: 10.1084/jem.20130783

109. Lesina M, Wörmann SM, Morton J, Diakopoulos KN, Korneeva O, Wimmer $\mathrm{M}$, et al. Rela Regulates CXCL1/CXCR2-dependent Oncogene-Induced Senescence in Murine Kras-driven Pancreatic Carcinogenesis. J In Vivo Clin Invest (2016) 126(8):2919-32. doi: 10.1172/JCI86477

110. Coppé JP, Kauser K, Campisi J, Beauséjour CM. Secretion of Vascular Endothelial Growth Factor by Primary Human Fibroblasts at Senescence. J Biol Chem (2006) 281(40):29568-74. doi: 10.1074/jbc.M603307200

111. Badache A, Hynes NE. Interleukin 6 Inhibits Proliferation and, in Cooperation With an Epidermal Growth Factor Receptor Autocrine Loop, Increases Migration of T47D Breast Cancer Cells. Cancer Res (2001) 61 (1):383-91

112. Sparmann A, Bar-Sagi D. Ras-Induced Interleukin-8 Expression Plays a Critical Role in Tumor Growth and Angiogenesis. Cancer Cell (2004) 6 (5):447-58. doi: 10.1016/j.ccr.2004.09.028
113. Ritschka B, Storer M, Mas A, Heinzmann F, Ortells MC, Morton JP, et al. The Senescence-Associated Secretory Phenotype Induces Cellular Plasticity and Tissue Regeneration. Genes Dev (2017) 31(2):172-83. doi: 10.1101/ gad.290635.116

114. Allavena P, Sica A, Solinas G, Porta C, Mantovani A. The Inflammatory Micro-Environment in Tumor Progression: The Role of Tumor-Associated Macrophages. Crit Rev Oncol Hematol (2008) 66(1):1-9. doi: 10.1016/ j.critrevonc.2007.07.004

115. Eggert T, Wolter K, Ji J, Ma C, Yevsa T, Klotz S, et al. Distinct Functions of Senescence-Associated Immune Responses in Liver Tumor Surveillance and Tumor Progression. Cancer Cell (2016) 30(4):533-47. doi: 10.1016/ j.ccell.2016.09.003

116. Myrianthopoulos V, Evangelou K, Vasileiou PVS, Cooks T, Vassilakopoulos TP, Pangalis GA, et al. Senescence and Senotherapeutics: A New Field in Cancer Therapy. Pharmacol Ther (2019) 193:31-49. doi: 10.1016/ j.pharmthera.2018.08.006

117. Milczarek M. The Premature Senescence in Breast Cancer Treatment Strategy. Cancers (2020) 12(7):1815. doi: 10.3390/cancers12071815

118. von Kobbe C. Targeting Senescent Cells: Approaches, Opportunities, Challenges. Aging (Albany NY) (2019) 11(24):12844-61. doi: 10.18632/ aging. 102557

119. Mosieniak G, Strzeszewska A. The Role of Cellular Senescence in Carcinogenesis and Antitumor Therapy. Postepy Biochem (2014) 60 (2):194-206.

120. Ewald JA, Desotelle JA, Wilding G, Jarrad DF. Therapy-Induced Senescence in Cancer. J Natl Cancer Inst (2010) 102(20):1536-46. doi: 10.1093/jnci/ djq364

121. Campisi J, Andersen JK, Kapahi P, Melov S. Cellular Senescence: A Link Between Cancer and Age-Related Degenerative Disease? Semin Cancer Biol (2011) 21(6):354-9. doi: 10.1016/j.semcancer.2011.09.001

122. Velarde MC, Demaria M. Targeting Senescent Cells: Possible Implications for Delaying Skin Aging: A Mini-Review. Gerontology (2016) 62(5):513-8. doi: $10.1159 / 000444877$

123. Crown J, O'Shaughnessy J, Gullo G. Emerging Targeted Therapies in TripleNegative Breast Cancer. Ann Oncol (2012) 23(Suppl 6):vi56-65. doi: 10.1093/annonc/mds196

124. Maiti R. Metronomic Chemotherapy. J Pharmacol Pharmacother (2014) 5 (3):186-92. doi: 10.4103/0976-500X.136098

125. Di Desidero T, Kerbel RS, Bocci G. Metronomic Chemotherapy for Triple Negative Breast Cancer? Aging (Albany NY) (2016) 8(4):573-4. doi: 10.18632/aging. 100947

126. Cazzaniga ME, Cortesi L, Ferzi A, Scaltriti L, Cicchiello F, Ciccarese M, et al. Metronomic Chemotherapy in Triple-Negative Metastatic Breast Cancer: The Future Is Now? Int J Breast Cancer 2017 (2017) p:1683060. doi: 10.1155/ 2017/1683060

127. Polychemotherapy for Early Breast Cancer: An Overview of the Randomised Trials. Early Breast Cancer Trialists' Collaborative Group. Lancet (1998) 352 (9132):930-42. doi: 10.1016/S0140-6736(98)03301-7

128. Janku F, McConkey DJ, Hong DS, Kurzrock R. Autophagy as a Target for Anticancer Therapy. Nat Rev Clin Oncol (2011) 8(9):528-39. doi: 10.1038/ nrclinonc.2011.71

129. Saab R. Cellular Senescence: Many Roads, One Final Destination. ScientificWorldJournal (2010) 10:727-41. doi: 10.1100/tsw.2010.68

130. Degenhardt K, Mathew R, Beaudoin B, Bray K, Anderson D, Chen G, et al. Autophagy Promotes Tumor Cell Survival and Restricts Necrosis, Inflammation, and Tumorigenesis. Cancer Cell (2006) 10(1):51-64. doi: 10.1016/j.ccr.2006.06.001

131. Watson JA, Watson CJ, McCrohan AM, Woodfine K, Tosetto M, McDaid J, et al. Generation of an Epigenetic Signature by Chronic Hypoxia in Prostate Cells. Hum Mol Genet (2009) 18(19):3594-604. doi: 10.1093/hmg/ddp307

132. Bojko A, Czarnecka-Herok J, Charzynska A, Dabrowski M, Sikora E. Diversity of the Senescence Phenotype of Cancer Cells Treated With Chemotherapeutic Agents. Cells (2019) 8(12). doi: 10.3390/cells8121501

133. Inao T, Kotani H, Iida Y, Kartika ID, Okimoto T, Tanino R, et al. Different Sensitivities of Senescent Breast Cancer Cells to Immune Cell-Mediated Cytotoxicity. Cancer Sci (2019) 110(9):2690-9. doi: 10.1111/cas.14116

134. Santarosa M, Del Col L, Tonin E, Caragnano A, Viel A, Maestro R. Premature Senescence is a Major Response to DNA Cross-Linking Agents 
in BRCA1-defective Cells: Implication for Tailored Treatments of BRCA1 Mutation Carriers. Mol Cancer Ther (2009) 8(4):844-54. doi: 10.1158/15357163.MCT-08-0951

135. Kavanagh EL, Lindsay S, Halasz M, Gubbins LC, Weiner-Gorzel K, Guang MHZ, et al. Protein and Chemotherapy Profiling of Extracellular Vesicles Harvested From Therapeutic Induced Senescent Triple Negative Breast Cancer Cells. Oncogenesis (2017) 6(10):e388. doi: 10.1038/oncsis. 2017.82

136. Gomes LR, Rocha CRR, Martins DJ, Fiore A, Kinker GS, Bruni-Cardoso A, et al. ATR Mediates Cisplatin Resistance in 3D-Cultured Breast Cancer Cells Via Translesion DNA Synthesis Modulation. Cell Death Dis (2019) 10 (6):459. doi: 10.1038/s41419-019-1689-8

137. Hill DP, Harper A, Malcolm J, McAndrews MS, Mockus SM, Patterson SE, et al. Cisplatin-Resistant Triple-Negative Breast Cancer Subtypes: Multiple Mechanisms of Resistance. BMC Cancer (2019) 19(1):1039. doi: 10.1186/ s12885-019-6278-9

138. Cerrito MG, De Giorgi M, Pelizzoni D, Bonomo SM, Digiacomo N, Scagliotti A, et al. Metronomic Combination of Vinorelbine and 5Fluorouracil is Able to Inhibit Triple-Negative Breast Cancer Cells. Results From the Proof-ofConcept VICTOR-0 Study. Oncotarget (2018) 9(44):27448-59. doi: 10.18632/oncotarget.25422

139. Poele RHT, Okorokov AL, Jardine L, Cummings J, Joel SP. DNA Damage is Able to Induce Senescence in Tumor Cells In Vitro and In Vivo. Cancer Res (2002) 62:1876-83.

140. Laine A, Sihto H, Come C, Rosenfeldt MT, Zwolinska A, Niemelä M, et al. Senescence Sensitivity of Breast Cancer Cells is Defined by Positive Feedback Loop Between CIP2A and E2F1. Cancer Discovery (2013) 3(2):182-97. doi: 10.1158/2159-8290.CD-12-0292

141. Jackson JG, Pant V, Li Q, Chang LL, Quintás-Cardama A, Garza D, et al. p53-mediated Senescence Impairs the Apoptotic Response to Chemotherapy and Clinical Outcome in Breast Cancer. Cancer Cell (2012) 21(6):793-806. doi: 10.1016/j.ccr.2012.04.027

142. Bertheau P, Plassa F, Espié M, Turpin E, de Roquancourt A, Marty M, et al. Effect of Mutated TP53 on Response of Advanced Breast Cancers to HighDose Chemotherapy. Lancet (2002) 360(9336):852-4. doi: 10.1016/S01406736(02)09969-5

143. Bertheau P, Turpin E, Rickman DS, Espié M, de Reyniès A, Feugeas JP, et al. Exquisite Sensitivity of TP53 Mutant and Basal Breast Cancers to a DoseDense Epirubicin-Cyclophosphamide Regimen. PloS Med (2007) 4(3):e90. doi: 10.1371/journal.pmed.0040090

144. Lachapelle J, Foulkes WD. Triple-Negative and Basal-Like Breast Cancer: Implications for Oncologists. Curr Oncol (2011) 18(4):161-4. doi: 10.3747/ co.v18i4.824

145. Straver ME, Glas AM, Hannemann J, Wesseling J, van de Vijver MJ, Rutgers EJ, et al. The 70-Gene Signature as a Response Predictor for Neoadjuvant Chemotherapy in Breast Cancer. Breast Cancer Res Treat (2010) 119(3):5518. doi: 10.1007/s10549-009-0333-1

146. Sanoff HK, Deal AM, Krishnamurthy J, Torrice C, Dillon P, Sorrentino J, et al. Effect of Cytotoxic Chemotherapy on Markers of Molecular Age in Patients With Breast Cancer. J Natl Cancer Inst (2014) 106(4):dju057. doi: 10.1093/jnci/dju057

147. Killock D. Chemotherapy: Life Gained, Years Lost? Nat Rev Clin Oncol (2014) 11(6):303. doi: 10.1038/nrclinonc.2014.67

148. Cupit-Link MC, Kirkland JL, Ness KK, Armstrong GT, Tchkonia T, LeBrasseur NK, et al. Biology of Premature Ageing in Survivors of Cancer. ESMO Open (2017) 2(5):e000250. doi: 10.1136/esmoopen-2017-000250

149. Gayle SS, Sahni JM, Webb BM, Weber-Bonk KL, Shively MS, Spina R, et al. Targeting BCL-xL Improves the Efficacy of Bromodomain and ExtraTerminal Protein Inhibitors in Triple-Negative Breast Cancer by Eliciting the Death of Senescent Cells. J Biol Chem (2019) 294(3):875-86. doi: 10.1074/ jbc.RA118.004712

150. Al-Hajj M, Wicha MS, Benito-Hernandez A, Morrison SJ, Clarke MF. Prospective Identification of Tumorigenic Breast Cancer Cells. Proc Natl Acad Sci USA (2003) 100(7):3983-8. doi: 10.1073/pnas.0530291100

151. Dalerba P, Cho RW, Clarke MF. Cancer Stem Cells: Models and Concepts. Annu Rev Med (2007) 58:267-84. doi: 10.1146/annurev.med.58.062105.204854

152. McDermott SP, Wicha MS. Targeting Breast Cancer Stem Cells. Mol Oncol (2010) 4(5):404-19. doi: 10.1016/j.molonc.2010.06.005
153. Li X, Lewis MT, Huang J, Gutierrez C, Osborne CK, Wu MF, et al. Intrinsic Resistance of Tumorigenic Breast Cancer Cells to Chemotherapy. J Natl Cancer Inst (2008) 100(9):672-9 doi: 10.1093/jnci/djn123

154. Bhola NE, Balko JM, Dugger TC, Kuba MG, Sánchez V, Sanders M, et al. Tgf- $\beta$ Inhibition Enhances Chemotherapy Action Against Triple-Negative Breast Cancer. J Clin Invest (2013) 123(3):1348-58. doi: 10.1172/JCI65416

155. Tominaga K, Suzuki HI. Tgf- $\beta$ Signaling in Cellular Senescence and AgingRelated Pathology. Int J Mol Sci (2019) 20(20). doi: 10.3390/ijms20205002

156. Pawlikowski JS, McBryan T, van Tuyn J, Drotar ME, Hewitt RN, Maier AB, et al. Wnt Signaling Potentiates Nevogenesis. Proc Natl Acad Sci USA (2013) 110p(40):16009-14. doi: 10.1073/pnas.1303491110

157. Sen P, Shah PP, Nativio R, Berger SL. Epigenetic Mechanisms of Longevity and Aging. Cell (2016) 166(4):822-39. doi: 10.1016/j.cell.2016.07.050

158. Cahu J, Bustany S, Sola B. Senescence-Associated Secretory Phenotype Favors the Emergence of Cancer Stem-Like Cells. Cell Death Dis (2012) 3 (12):e446. doi: 10.1038/cddis.2012.183

159. Liepe J, Marino F, Sidney J, Jeko A, Bunting DE, Sette A, et al. A Large Fraction of HLA Class I Ligands are Proteasome-Generated Spliced Peptides. Science (2016) 354(6310):354-8. doi: 10.1126/science.aaf4384

160. Vernot JP. Senescence-Associated Pro-inflammatory Cytokines and Tumor Cell Plasticity. Front Mol Biosci (2020) 7:63. doi: 10.3389/ fmolb.2020.00063

161. Gerashchenko BI, Salmina K, Eglitis J, Huna A, Grjunberga V, Erenpreisa J. Disentangling the Aneuploidy and Senescence Paradoxes: A Study of Triploid Breast Cancers non-Responsive to Neoadjuvant Therapy. Histochem Cell Biol (2016) 145(4):497-508. doi: 10.1007/s00418-016-1415-x

162. Liu X, Hoft DF, Peng G. Senescent T Cells Within Suppressive Tumor Microenvironments: Emerging Target for Tumor Immunotherapy. J Clin Invest (2020) 130(3):1073-83. doi: 10.1172/JCI133679

163. Zitvogel L, Kepp O, Kroemer G. Immune Parameters Affecting the Efficacy of Chemotherapeutic Regimens. Nat Rev Clin Oncol (2011) 8(3):151-60. doi: 10.1038/nrclinonc.2010.223

164. Demaria S, Romano E, Brackstone M, Formenti SC. Immune Induction Strategies to Enhance Responses to PD-1 Blockade: Lessons From the TONIC Trial. J Immunother Cancer (2019) 7(1):318. doi: 10.1186/s40425019-0783-x

165. Battram AM, Bachiller M, Martín-Antonio B. Senescence in the Development and Response to Cancer With Immunotherapy: A DoubleEdged Sword. Int J Mol Sci (2020) 21(12). doi: 10.3390/ijms21124346

166. Nardella C, Clohessy JG, Alimonti A, Pandolfi PP. Pro-Senescence Therapy for Cancer Treatment. Nat Rev Cancer (2011) 11(7):503-11. doi: 10.1038/ nrc3057

167. Wang M, Wu W, Wu W, Rosidi B, Zhang L, Wang H, et al. PARP-1 and $\mathrm{Ku}$ Compete for Repair of DNA Double Strand Breaks by Distinct NHEJ Pathways. Nucleic Acids Res (2006) 34(21):6170-82. doi: 10.1093/ nar/gkl840

168. Lupo B, Trusolino L. Inhibition of Poly(ADP-Ribosyl)Ation in Cancer: Old and New Paradigms Revisited. Biochim Biophys Acta (2014) 1846(1):201-15. doi: 10.1016/j.bbcan.2014.07.004

169. Fleury H, Carmona E, Morin VG, Meunier L, Masson JY, Tonin PN, et al. Cumulative Defects in DNA Repair Pathways Drive the PARP Inhibitor Response in High-Grade Serous Epithelial Ovarian Cancer Cell Lines. Oncotarget (2017) 8(25):40152-68. doi: 10.18632/oncotarget.10308

170. Ledermann J, Harter P, Gourley C, Friedlander M, Vergote I, Rustin G, et al. Olaparib Maintenance Therapy in Platinum-Sensitive Relapsed Ovarian Cancer. N Engl J Med (2012) 366(15):1382-92. doi: 10.1056/ NEJMoa1105535

171. Han Y, Yu X, Li S, Tian Y, Liu C. New Perspectives for Resistance to PARP Inhibitors in Triple-Negative Breast Cancer. Front Oncol (2020) 10:578095. doi: 10.3389/fonc.2020.578095

172. Kam Y, Das T, Tian H, Foroutan P, Ruiz E, Martinez G, et al. Sweat But No Gain: Inhibiting Proliferation of Multidrug Resistant Cancer Cells With "Ersatzdroges". Int J Cancer (2015) 136(4):E188-96. doi: 10.1002/ijc.29158

173. Abbadie C, Pluquet O. Unfolded Protein Response (Upr) Controls Major Senescence Hallmarks. Trends Biochem Sci (2020) 45(5):371-4. doi: 10.1016/ j.tibs.2020.02.005

174. Pluquet O, Pourtier A, Abbadie C. The Unfolded Protein Response and Cellular Senescence. A Review in the Theme: Cellular Mechanisms of 
Endoplasmic Reticulum Stress Signaling in Health and Disease. Am J Physiol Cell Physiol (2015) 308(6):C415-25. doi: 10.1152/ajpcell.00334.2014

175. Kwon SM, Hong SM, Lee YK, Min S, Yoon G. Metabolic Features and Regulation in Cell Senescence. BMB Rep (2019) 52(1):5-12. doi: 10.5483/ BMBRep.2019.52.1.291

176. Gatenby RA, Zhang J, Brown JS. First Strike-Second Strike Strategies in Metastatic Cancer: Lessons From the Evolutionary Dynamics of Extinction. Cancer Res (2019) 79(13):3174-7. doi: 10.1158/0008-5472.can-19-0807

177. Kaznatcheev A, Vander Velde R, Scott JG, Basanta D. Cancer Treatment Scheduling and Dynamic Heterogeneity in Social Dilemmas of Tumour Acidity and Vasculature. Br J Cancer (2017) 116(6):785-92. doi: 10.1038/ bjc. 2017.5

178. Gerlee P, Altrock PM. Extinction Rates in Tumour Public Goods Games. J R Soc Interface (2017) 14(134). doi: 10.1098/rsif.2017.0342

179. Archetti M. Evolutionary Game Theory of Growth Factor Production: Implications for Tumour Heterogeneity and Resistance to Therapies. $\mathrm{Br} \mathrm{J}$ Cancer (2013) 109(4):1056-62. doi: 10.1038/bjc.2013.336

180. Archetti M, Ferraro DA, Christofori G. Heterogeneity for IGF-II Production Maintained by Public Goods Dynamics in Neuroendocrine Pancreatic
Cancer. Proc Natl Acad Sci USA (2015) 112p(6):1833-8. doi: 10.1073/pnas. 1414653112

181. Malaquin N, Martinez A, Rodier F. Keeping the Senescence Secretome Under Control: Molecular Reins on the Senescence-Associated Secretory Phenotype. Exp Gerontol (2016) 82:39-49. doi: 10.1016/ j.exger.2016.05.010

Conflict of Interest: The authors declare that the research was conducted in the absence of any commercial or financial relationships that could be construed as a potential conflict of interest.

Copyright (C) 2021 Chakrabarty, Chakraborty, Bhattacharya and Chowdhury. This is an open-access article distributed under the terms of the Creative Commons Attribution License (CC BY). The use, distribution or reproduction in other forums is permitted, provided the original author(s) and the copyright owner(s) are credited and that the original publication in this journal is cited, in accordance with accepted academic practice. No use, distribution or reproduction is permitted which does not comply with these terms. 